\title{
SEM/EDS Trace Analysis: Limits Imposed by Fluorescence of the Detector
}

\author{
Dale Newbury ${ }^{1}$, Nicholas Ritchie ${ }^{1}$, Michael Mengason ${ }^{1}$, and Keana Scott $^{1}$ \\ 1. National Institute of Standards and Technology, Gaithersburg, MD, USA.
}

Electron-excited x-ray microanalysis performed with the scanning electron microscope and energy dispersive $x$-ray spectrometry (SEM/EDS) using NIST DTSA-II for spectrum processing has been shown to be capable of the same degrees of accuracy and precision as that achieved with high spectral resolution wavelength dispersive spectrometry (WDS), and at lower dose [1,2]. High-count EDS spectra (e.g., > 10 million counts integrated from $0.1 \mathrm{keV}$ to $\mathrm{E}_{0}$ ) that can be recorded in modest time (e.g., $\sim 100 \mathrm{~s}$ to $1000 \mathrm{~s}$ ) with the high-throughput silicon drift detector (SDD) enable trace measurements with concentration limits of detection ranging from 0.0001 to 0.0005 mass fraction (100 to 500 parts per million (ppm)) depending on the elemental species, matrix composition, and peak interference [3]. However, certain elements are subject to elevated limits of detection that result from artifacts arising from X-ray induced fluorescence of the materials of construction of the detector. Examples include: (1) Si from various sources, including the "dead layer" at the first surface of the detector, the etched Si grid used to support certain vacuum isolation windows, and the window itself if $\mathrm{Si}_{3} \mathrm{~N}_{4}$, which also contributes an artifact N signal; (2) C from a polymer window; and (3) Al or other elements from the collimator. Figure 1 shows the EDS spectrum (Si-grid supported polymer window) of a high purity graphite target that reveals detection of a trace artifact level of $\mathrm{Si}$. The limit of detection for $\mathrm{Si}$ as measured by WDS was below $1 \times 10^{-5}$ mass concentration (10 parts per million, ppm). If this spurious $\mathrm{Si}$ intensity is assumed to originate from uniformly distributed $\mathrm{Si}$ within the $\mathrm{C}$ specimen, quantitative analysis with NIST DTSA-II gives the apparent concentration as $\mathrm{Si}=2.3$ $\mathrm{x} 10^{-4}(230 \mathrm{ppm})$. (Note that $\mathrm{Al}=8.7 \times 10^{-5}(87 \mathrm{ppm})$ is also detected as an artifact.) A similar measurement of high purity silicon with the same polymer window (carbon-containing) revealed an artifact carbon kratio of 0.0009 which corresponds to an apparent concentration level of 0.007 mass fraction (7000 ppm). The artifact carbon concentration level is substantially elevated as a consequence of the large absorption correction that occurs when $\mathrm{C}$ is assumed to be uniformly distributed in $\mathrm{Si}(\mathrm{A}=9.4$, due to the close proximity of the Si L-edge below the $\mathrm{C}$ K peak). WDS evaluation of this crystal revealed that $\mathrm{C}$ was below the limit of detection, which was estimated to be $8.5 \times 10^{-4}$ ( $\left.850 \mathrm{ppm}\right)$.

The obvious solution to avoid or at least minimize these artifacts involves eliminating the sources of spurious radiation wherever possible. A significant reduction in the artifact carbon signal can be obtained by using an $\mathrm{Si}_{3} \mathrm{~N}_{4}$ window, as shown in Figure 2, which compares spectra for a low carbon steel $(<10$ ppm) with a carburized outer rim. Another option would be a windowless EDS on a high vacuum SEM to completely eliminate the contributions from the window materials. Note that the unavoidable fluorescence from the "Si dead layer" at the entrance surface of the detector sets the ultimate limit on the Si detection limit.

References:

[1] D. Newbury and N. Ritchie, J. Materials Sci. 50 (2015), p. 493.

[2] N. Ritchie, NIST DTSA-II available free at: www.cstl.nist.gov/div837/837.02/epq/dtsa2/index.html

[3] D. Newbury and N. Ritchie, Micros. Microanal. 22 (2016), p. 520. 


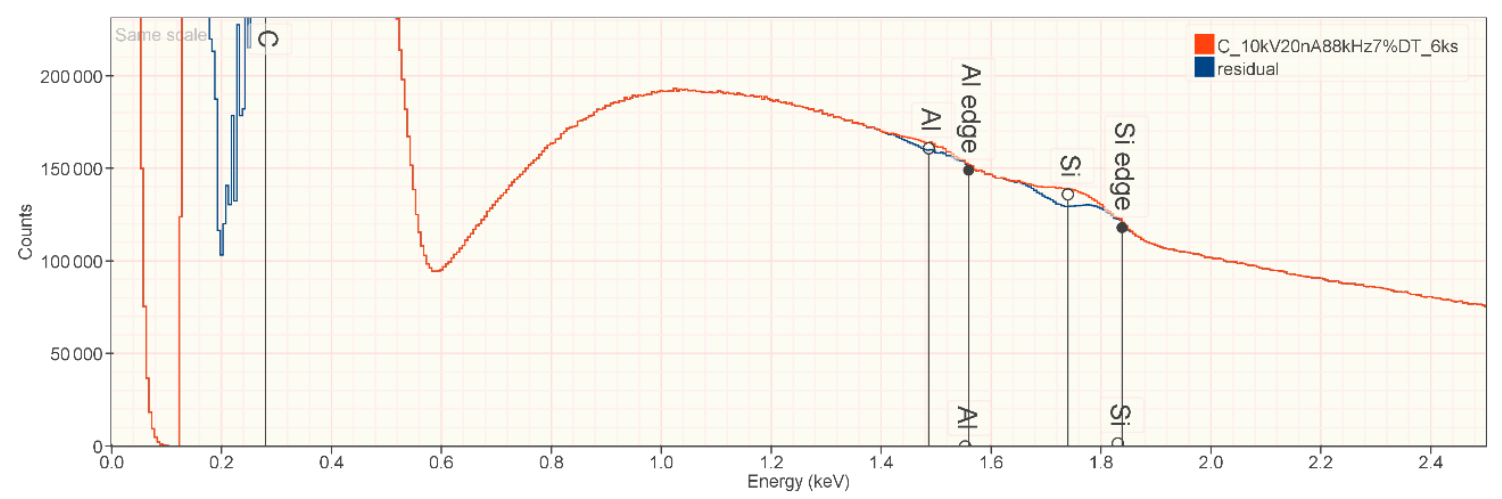

Figure 1. EDS spectrum (Si-grid polymer window) of high purity graphite and DTSA-II peak fitting residual; $\mathrm{E}_{0}=10 \mathrm{keV}$; spectrum integral from $0.1-10 \mathrm{keV}=673$ million counts. The apparent concentrations are $\mathrm{Si}=2.3 \times 10^{-4}(230 \mathrm{ppm})$ and $\mathrm{Al}=8.7 \times 10^{-5}(87 \mathrm{ppm})$.

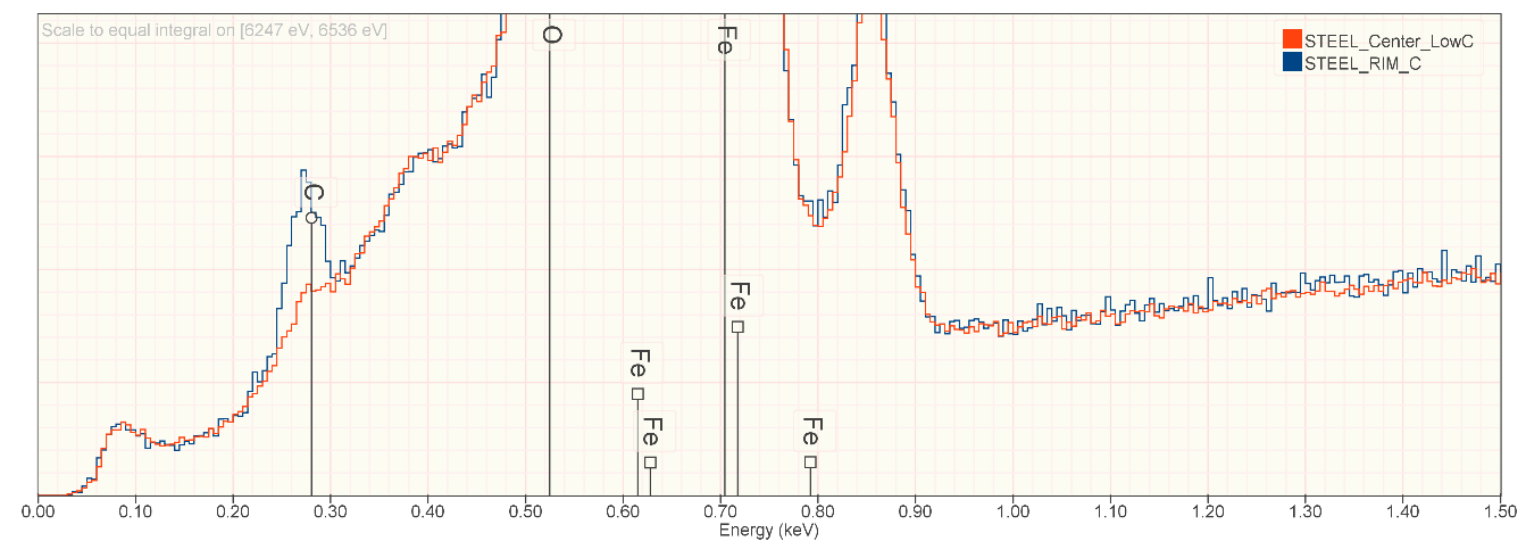

Figure 2. EDS spectra ( $\mathrm{Si}_{3} \mathrm{~N}_{4}$ window) of a low carbon steel (<0.00001 (10 ppm); red spectrum) with a carburized rim (blue spectrum); $\mathrm{E}_{0}=10 \mathrm{keV}$; spectrum integral from $0.1-10 \mathrm{keV}=3$ million counts. The maximum $C$ concentration measured in the carburized rim is $0.0117 \pm 0.0015(1.17 \pm$ 0.15 weight percent). 